\title{
Comparison of Antioxidant Properties of Coconut Testa Flour of Selected Local Coconut Cultivars of Sri Lanka ${ }^{\dagger}$
}

\author{
Sanjila Marasinghe ${ }^{1,2, *}$, Nazrin Marikkar ${ }^{1}$, Swarna Wimalasiri ${ }^{3}$, Lalith Jayasinghe ${ }^{1}$ \\ and Ruvini Liyanage ${ }^{1}$ \\ 1 National Institute of Fundamental Studies, Kandy 20000, Sri Lanka; nazrin.ma@nifs.ac.lk (N.M.); \\ lalith.ja@nifs.ac.lk (L.J.); ruvini.li@nifs.ac.lk (R.L.) \\ 2 Postgraduate Institute of Science, University of Peradeniya, Peradeniya 20400, Sri Lanka \\ 3 Faculty of Agriculture, University of Peradeniya, Peradeniya 20400, Sri Lanka; \\ swarna60@yahoo.com (S.W.) \\ * Correspondence: sanjila.marasinghe@gmail.com \\ + Presented at the third International Tropical Agriculture Conference (TROPAG 2019), Brisbane, Australia, \\ 11-13 November 2019.
}

Published: 14 March 2020

\begin{abstract}
Coconut testa is the thin brown colored outer skin of coconut endosperm. It is often peeled off from the kernel during coconut processing due to unfavorable brown colour it might impart on finished products. An attempt was made to utilize coconut testa to produce defatted flour as a substitute for wheat flour in bakery products. Aim of this study was to compare the total phenolic content (TPC) and ferric reducing antioxidant power (FRAP) of coconut testa flour of four local cultivars namely san raman (SR), gon thembili (GT), ran thembili (RT), TallxTall (TxT) against the commercial hybrid (COM) grown in Sri Lanka. Hundred grams of coconut testa flour produced from partially defatted coconut pairings was extracted with 70\% ethanol-water mixture. The TPC and FRAP assays were conducted using a 96 well micro plate reader. Percentage yield (\%) of crude extracts of SR, RT, GT, TXT and COM were 8.26, 6.87, 7.66, 8.06 and 11.17, respectively. The maximum TPC content was observed in TXT $(62.58 \pm 5.99 \mathrm{mg}$ GAE/g of extract) while the minimum TPC content was recorded for GT ( $27.53 \pm 4.54 \mathrm{mg} \mathrm{GAE} / \mathrm{g}$ of extract). The lowest FRAP value was observed for SR $(0.26 \pm 0.02 \mathrm{mmol} \mathrm{FeSO} 4 / \mathrm{g}$ of extract $)$ while the highest FRAP value was observed for COM $(0.67 \pm 0.00 \mathrm{mmol} \mathrm{FeSO} / \mathrm{g}$ of extract) variety. In conclusion, coconut testa flour is a rich source of phenolics and antioxidants. The presence of these bioactives would make it a potential functional ingredient in food processing industry.
\end{abstract}

Keywords: coconut testa; phenolic; antioxidants; extract; yield

Author Contributions: S.M. is a postgraduate research student who conducted the research, analysed the data and wrote the abstract. N.M. and S.W. are her postgraduate research supervisors who guided her and corrected the abstract. L.J. and R.L. are collaborators of this research who provided chemicals and support for this research.

Funding: This research received funding from National Institute of Fundamental Studies, Sri Lanka. 
Acknowledgments: Authors greatly acknowledge Coconut Research Institute, Lunuwila for providing coconut testa samples to conduct this research.

Conflicts of Interest: The authors declare no conflict of interest.

(c) 2019 by the authors. Licensee MDPI, Basel, Switzerland. This article is an open access article distributed under the terms and conditions of the Creative Commons Attribution (CC BY) license (http://creativecommons.org/licenses/by/4.0/). 